or negatively charged as a whole, there is an excess of positively or negatively charged drops. The following table gives the charge per drop based on the measurement of about two thousand drops. In making the tabulations all drops were neglected the charge of which was less than 0.06 e.s.u.

\begin{tabular}{|c|c|c|c|c|c|c|}
\hline & \multicolumn{6}{|c|}{ Charge per drop (e.s.u.) } \\
\hline & \multicolumn{3}{|c|}{$\begin{array}{c}\text { Pogitively charged } \\
\text { drops. }\end{array}$} & \multicolumn{3}{|c|}{$\begin{array}{l}\text { Negatively charged } \\
\text { drops. }\end{array}$} \\
\hline & Mean & $\begin{array}{l}\text { Absolute } \\
\text { max. }\end{array}$ & $\begin{array}{l}\text { Mean } \\
\max .\end{array}$ & Mean & $\begin{array}{l}\text { Absolute } \\
\text { max. }\end{array}$ & $\begin{array}{l}\text { Mean } \\
\max .\end{array}$ \\
\hline $\begin{array}{l}\text { Non-thunderstorm } \\
\text { rain . O O O } \\
\text { Thunderstorm }\end{array}$ & 0.64 & $1 \cdot 95$ & $1 \cdot 23$ & 0.67 & $2 \cdot 41$ & $1 \cdot 24$ \\
\hline rain $\quad \ldots \quad \ldots$ & $0 \cdot 69$ & $2 \cdot 44$ & $1 \cdot 82$ & $0 \cdot 73$ & $3 \cdot 74$ & $2 \cdot 26$ \\
\hline
\end{tabular}

A detailed analysis of the observations with discussion will be given in our forthcoming memoir on the subject.

The Observatory, Bombay.

$$
\text { S. K. BANERJT. }
$$$$
\text { S. R. LFLe. }
$$

Nov. 14.

\section{Diamagnetism of Thin Films of Bismuth}

Aт Prof. W. Gerlach's suggestion I have recently investigated the behaviour of the magnetic susceptibility of bismuth when measured in the form of thin films. A modified form of the Faraday method was employed, the measuring system consisting of a flat cross with four equal arms about $15 \mathrm{~mm}$. long and $5 \mathrm{~mm}$. wide, the arms being set at about $90^{\circ}$ to one another. This system was constructed of glass about $0.1 \mathrm{~mm}$. thick. A fine glass wire through the centre of the cross and perpendicular to its plane carried a small galvanometer mirror; the system was suspended from a torsion head by means of a fine quartz fibre and was thus free to turn about the glass wire as axis. The cross hung in an inhomogeneous, but symmetrical, magnetic field formed by two $60^{\circ}$ wedge-shaped pole pieces such that each pole piece occupied the space between two adjacent arms of the cross. The plane of the cross was horizontal and parallel to the lines of force, the centre of the cross and field system being coincident. The gap between the pole pieces was about $10 \mathrm{~mm}$. In the magnetic field the cross would take up a very definite position of equilibrium and this point was made the zero point of the system when no field was acting. A film of bismuth was now deposited on one long arm of the cross (that is, about $30 \mathrm{~mm}$. long) thus upsetting the equilibrium and causing the system to be deflected, which in turn was brought back to its initial zero position by means of the torsion head, the angle of deflection being determined by a telescope and scale in the usual way.

The films were produced by evaporation from an electric furnace such that they were about the same size as one long arm of the cross, that is, about $30 \mathrm{~mm}$. $\times 5 \mathrm{~mm}$., and of very uniform thickness. The deposition of the films and measurements were made in vacuum; it was impossible however to outgas the cross system. The procedure was first to deposit a very thin sensitising film, the magnetic properties of which were negligible, in order to have a more or less definite surface on which to deposit the thicker films. A film was now deposited and the deflection measured; over this was now deposited a very much thicker film and the deflection again measured, always from the initial zero position in the same field. Of course an intermediate film between the thick and the thin one could be deposited and measured if desired. If $\theta, K$ and $d$ refer respectively to deflection, volume susceptibility and thickness of a given film, since the field remains the same for two or more given measurements,

$$
\begin{gathered}
\theta \propto K d \\
\text { or } \frac{K_{2}}{K_{1}}=\frac{\theta_{2}}{\theta_{2}} \cdot \frac{d_{1}}{d_{1}+d_{2}}
\end{gathered}
$$

Hence in order to compare the susceptibility of a thin and a thick film we must know the ratio of $d_{1}$ to $d_{2}$. By means of a shutter in the apparatus the time of deposition of the films could be accurately controlled. Both films are deposited under the same conditions of temperature and pressure in the apparatus. In order to give absolute values the thickness of the final film $\left(d_{1}+d_{2}\right)$ was determined in the usual way by weighing. From the times of deposition the ratio $d_{1}$ to $d_{2}$ is known and $d_{1}$ and $d_{1}+d_{2}$ are known absolutely. The susceptibility of the thin film is then known in terms of the thick one.

Lack of space prevents giving a detailed table of results but in some forty determinations ranging in film thickness from $0.2 \mu$ to $15 \mu$ no variation of the susceptibility could be found. Certainly the fluctuations between readings is rather large (some 12 per cent) but these readings are all grouped around a mean value which is quite constant. I believe we can draw the conclusion that, in the given range, the susceptibility of bismuth remains constant.

A considerable amount of work on the susceptibility of colloidal powder of bismuth and other metals (Sb, Ag, Au) has been done by Vaidyanathan, ${ }^{1}$ $\mathrm{RaO}^{2}$ and others. These authors find that with decreasing particle size the diamagnetic susceptibility decreases and have advanced the hypothesis that the susceptibility becomes a function of the particle size when this is less than $10 \mu$. While Mathur and Varma $^{3}$ in a careful series of tests have shown that a large part of this decrease in bismuth is due to oxidation, $\mathrm{Rao}^{2}$ still finds a change when the oxide is removed as completely as possible. If, however, diamagnetism actually depends on particle size, we should expect the experiment described here to show it, since we know that a thin film is composed of small crystallites the size of which decreases as the film thickness is decreased.

I would suggest that the hypothesis recently advanced by Seemann and Kussmann to explain the effect of cold work on the susceptibility of metals might also account for the effect observed in colloidal powder. The process of mechanical colloidalisation (that is, grinding) could be looked upon as cold working, which sets free ferromagnetic impurities in the metal giving rise to a decrease in diamagnetism. Melting the colloidal powder (as Rao has done) would again render the impurity inactive giving rise to an increase in diamagnetism as observed. It might be possible to make a direct check on this point by measuring the susceptibility of each powder at various field strengths, since as the particle size decreases the susceptibility should show more and more variation with the field.

Institute of Physics, C. T. LANE.

University of Munich.

1 Vaidyanathan, Ind. J. Phys., 5, 559; 1930.

'Rao, ibid., 6, 241; 1931 ,

- Seemann and Kussmann, Naturioiss., 18, 309 ; 1931.

No. 3296, VoL. 130] 